\title{
Influence of Alloying Elements on Sulfide Formation in Lead Free Bronze Castings with Dispersed Sulfide Particles
}

\author{
Toru Maruyama ${ }^{1}$, Hiroyuki $\mathrm{Abe}^{2}$, Kazuteru Hirose ${ }^{3}$, Ryozo Matsubayashi ${ }^{3}$ and Takeshi Kobayashi ${ }^{4}$ \\ ${ }^{1}$ Department of Chemistry and Materials Engineering, Faculty of Chemistry, Materials and Bioengineering, \\ Kansai University, Suita 564-8680, Japan \\ ${ }^{2}$ North Eastern Industrial Research Center of Shiga Prefecture, Hikone 522-0037, Japan \\ ${ }^{3}$ Shiga Valve Cooperative, Hikone 522-0037, Japan \\ ${ }^{4}$ Kansai University, Suita 564-8680, Japan
}

\begin{abstract}
The influence of the zinc sulfide ratio in the sulfide particle in the lead free bronze castings on the machinability is studied. Also, the influence of alloying elements of the zinc sulfide ratio of the sulfide particle is studied for understanding the mechanism of the zinc sulfide formation during the solidification. The zinc sulfide ratio is evaluated with the analysis of the microstructure in the lead free bronze prepared by the sand mold casting. The condition in which the zinc sulfide stably exists during the solidification is estimated with thermodynamic calculation. The machinability is improved with the decrement of the zinc sulfide ratio. The sulfide is formed as the copper sulfide and the zinc sulfide through eutectic reaction, and also appears as the liquid phase through monotectic reaction. The zinc sulfide is formed with the copper sulfide at the temperature, at which the zinc sulfide was predicted to be unstable by the thermodynamic calculation. The ratio of the zinc sulfide increases with increasing zinc content. Tin does not affect the zinc sulfide ratio when the tin content is less than about 4 mass \%. There is no effect of nickel on the zinc sulfide ratio. [doi:10.2320/matertrans.F-M2011835]
\end{abstract}

(Received November 29, 2010; Accepted September 7, 2011; Published January 12, 2012)

Keywords: castings, copper alloy, copper sulfide, eutectic reaction, lead free bronze, machinability, microstructural control, monotectic reaction, solidification, zinc sulfide

\section{Introduction}

The sulfide dispersed lead free bronze, ${ }^{1-4)}$ such as JIS CAC411, is one of substitute materials for the conventional leaded bronze $\mathrm{e}^{5,6)}$ for plumbing products. The amount of porosity of the lead free bronze castings with dispersed sulfide particles is smaller than that of the conventional leaded bronze castings because the solidification type of the lead free bronze is the skin formation type of solidification. ${ }^{1-3)}$ The lead free bronze is expected to be cast by the permanent mold casting due to the small solidification temperature range, ${ }^{2,7,8)}$ and to be used for a heat resistant copper alloy because the sulfide dispersed lead free bronze castings do not contain elements of low melting point, such as lead and bismuth. The sulfide dispersed lead free bronze is anticipated to be more versatile than the conventional leaded bronzes, for example, JIS CAC406, CDA C83600, DIN CC491K. ${ }^{5,6)}$

However, the machinability of the sulfide dispersed lead free bronze decreases with increasing zinc content. ${ }^{1)}$ The authors $^{1-3}$ ) have reported on the effect of the alloying elements on the properties of the lead free bronze castings. However, there have been no reports to clarify the reason why the machinability is decreased with increasing zinc content. It is very important to clarify the reason of the decrease in the machinability with increasing zinc content to improve the machinability of the sulfide dispersed lead free bronze castings.

In the previous reports, ${ }^{1-3)}$ alloying elements, such as zinc, tin, and nickel, increased the matrix hardness to reduce the machinability. Among them, the machinability is mostly reduced by the zinc addition, because zinc is included in the sulfide particle as the zinc sulfide, which is harder than the copper matrix.
It is necessary to clarify the detail of the reason of the deterioration of the machinability with increasing zinc content. Since the zinc sulfide is harder than the copper matrix, the increment of the zinc sulfide may deteriorate the machinability. Therefore, it is important to clarify the relationship between the amount of zinc sulfide in the sulfide particle and the machinability.

In the present study, the effect of the zinc sulfide ratio in the sulfide particle on the machinability is studied. In addition, the conditions, such as the zinc content and the temperature, in which the zinc sulfide stably exists during the solidification are estimated by thermodynamic calculation. The ratio of the zinc sulfide in the sulfide particles is evaluated by the microstructural analysis, and the effect of alloying elements on the zinc sulfide ratio is examined.

\section{Experimental Procedure}

For preparing specimens, a high frequency induction furnace with the maximum power of $200 \mathrm{kVA}$ was used as well as previous report. ${ }^{1)}$ A clay-graphite crucible was used for melting. Pure metals of $\mathrm{Cu}, \mathrm{Sn}, \mathrm{Zn}$ and $\mathrm{Ni}$ were used for melting materials, and the mother alloy containing sulfur was also used for addition of sulfur. Table 1 shows chemical compositions of the sulfide dispersed lead free bronze. The amount of impurity elements, such as $\mathrm{Al}, \mathrm{Sb}, \mathrm{Fe}$, and $\mathrm{P}$, was less than 0.3 mass $\%$ in total. The $\mathrm{Cu}-15$ mass $\% \mathrm{P}$ alloy was added into the melt for de-oxidization, and also $\mathrm{C}_{2} \mathrm{Cl}_{6}$ was added into the melt for de-hydrogenating if necessary. The temperature of the melt was controlled below $1493 \mathrm{~K}$ $\left(1220^{\circ} \mathrm{C}\right)$, and the melt was cast at $1427 \mathrm{~K}\left(1150^{\circ} \mathrm{C}\right)$ into the sand mold (the furan resin mold) with the inner diameter of $25 \mathrm{~mm}$. The castings were subjected to the microstructure observation through optical microscope and scanning 
Table 1 Chemical compositions of sulfide dispersed lead free bonze castings (mass \%).

\begin{tabular}{ccccc}
\hline Sample No. & $\mathrm{Sn}$ & $\mathrm{Zn}$ & $\mathrm{Ni}$ & $\mathrm{S}$ \\
\hline ZN-1 & 3.10 & $<0.05$ & 1.00 & 0.46 \\
ZN-2 & 3.50 & 1.2 & 0.97 & 0.45 \\
ZN-3 & 3.30 & 2.5 & 0.98 & 0.44 \\
ZN-4 & 3.30 & 3.3 & 0.95 & 0.43 \\
ZN-5 & 3.20 & 4.0 & 0.90 & 0.45 \\
ZN-6 & 3.30 & 5.9 & 1.00 & 0.45 \\
ZN-7 & 3.20 & 6.9 & 0.97 & 0.45 \\
ZN-8 & 3.30 & 7.6 & 1.00 & 0.46 \\
\hline SN-1 & 1.04 & 2.5 & 1.02 & 0.48 \\
SN-2 & 1.88 & 2.4 & 0.99 & 0.47 \\
SN-3 & 4.85 & 2.4 & 0.96 & 0.47 \\
SN-4 & 5.57 & 2.6 & 0.97 & 0.47 \\
\hline NI-1 & 3.10 & 2.0 & 0.21 & 0.48 \\
NI-2 & 2.90 & 2.1 & 0.50 & 0.46 \\
NI-3 & 2.80 & 1.9 & 1.88 & 0.45 \\
\hline S-1 & 3.00 & 2.1 & 1.03 & 0.27 \\
S-2 & 2.80 & 2.1 & 0.96 & 0.35 \\
S-3 & 2.90 & 2.3 & 0.93 & 0.57 \\
S-4 & 2.80 & 2.3 & 0.95 & 0.69 \\
\hline
\end{tabular}

electron microscope (SEM), and the element mapping by the wavelength-dispersive X-ray spectrometer (WDX). The ratio of zinc sulfide in the sulfide particle was measured in the optical microstructure by the image analysis. The area of an image was $0.291 \mathrm{~mm}^{2}$. The 15 images were measured for each sample. Hardness was measured by using B scale of a Rockwell hardness tester. The hardness of each sample was determined as the average of six measurements. The machinability was evaluated with the electric power consumption during cutting by a lathe, ${ }^{1)}$ and was expressed as the cutting index, $I_{\mathrm{C}}$, given by

$$
I_{\mathrm{C}}=E_{0} / E,
$$

where $E$ is the electric power consumption during the lathe cutting of the test specimen, and $E_{0}$ is the electric power consumption during the lathe cutting of the conventional leaded bronze castings with the typical composition of $\mathrm{Cu}-$ 5 mass $\%$ Sn-5 mass $\% \mathrm{Zn}-5$ mass $\% \mathrm{~Pb}$.

\section{Thermodynamic Calculation}

To understand the criterion for the stability of the zinc sulfide, the conditions, such as the zinc content and the temperature, in which the sulfide was stably existed, were calculated. The reaction to form the sulfide is given by the eq. (2).

$$
2 \mathrm{Cu}(1)+\mathrm{ZnS}(\mathrm{s})=\mathrm{Cu}_{2} \mathrm{~S}(\mathrm{~s})+\mathrm{Zn}(\mathrm{l}) .
$$

The Gibbs free energy change occurred in the above reaction is given by,

$$
\Delta G^{\circ} / \mathrm{kJ}=-0.0765 T+143.67^{9)} .
$$

The equilibrium constant, $K_{p}$, is

$$
K_{p}=a_{\mathrm{Cu}_{2} \mathrm{~S}} a_{\mathrm{Zn}} / a_{\mathrm{Cu}}{ }^{2} a_{\mathrm{ZnS}} .
$$
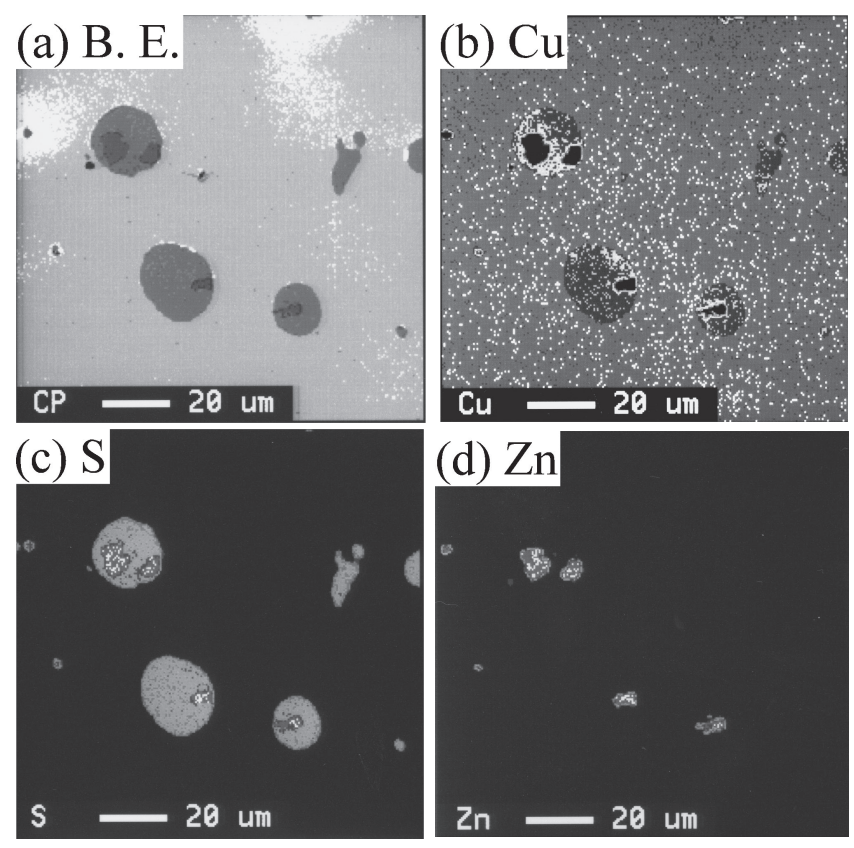

Fig. 1 Backscattered electron image, and elemental maps of $\mathrm{ZN}-4$ obtained by WDX.

Activities of copper sulfide and zinc sulfide $\left(a_{\mathrm{Cu}_{2} \mathrm{~S}}\right.$ and $\left.a_{\mathrm{ZnS}}\right)$ were assumed to be one because they were in the solid state. The activity of copper, $a_{\mathrm{Cu}}$, was calculated by Raoult's low, and was equated to the molar fraction of copper $\left(N_{\mathrm{Cu}}\right)$. The activity of zinc, $a_{\mathrm{Zn}}$, in the molten copper alloy was calculated by the relational equation given by Azakami and Yazawa $^{10)}$ as follows:

$$
R T \ln \gamma_{\mathrm{Zn}}=-26.8 \mathrm{~kJ} \mathrm{~mol}^{-1},
$$

where $R$ is the gas constant $\left(\mathrm{JK}^{-1} \mathrm{~mol}^{-1}\right), T$ is the absolute temperature $(\mathrm{K})$, and $\gamma_{\mathrm{Zn}}$ is the activity coefficient of zinc.

\section{Results and Discussions}

\subsection{Zinc sulfide in sulfide particle}

Figure 1 shows the backscattered electron image (a) and the element mapping images of $\mathrm{Cu}$ (b), S (c), and $\mathrm{Zn}$ (d) obtained by WDX. The sample number is ZN-4. Spherical particles are dispersed in the matrix. These particles contain copper, zinc and sulfur. The region containing copper and sulfur corresponds to the copper sulfide, and the region containing zinc and sulfur corresponds to the zinc sulfide. These sulfides were identified by the X-ray diffraction analysis. $^{4)}$

Figure 2 shows the change in the microstructure of the sulfide with zinc content. In the alloy, the tin content was 3.13.5 mass $\%$, the nickel content was 1.0 mass $\%$, and the sulfur content was $0.43-0.46$ mass $\%$. The light gray region is the copper sulfide and the dark gray region is the zinc sulfide in the microstructure. The sulfide in Fig. 2(a) was formed through the eutectic reaction. When zinc is contained in the alloy, zinc oxides are dispersed in the alloy to act as nucleation sites of the eutectic reaction. In the present alloy, however, zinc is not contained in the alloy. Therefore, some oxides other than the zinc oxide might act as the nucleation sites of the eutectic reaction. The eutectic reaction with the 


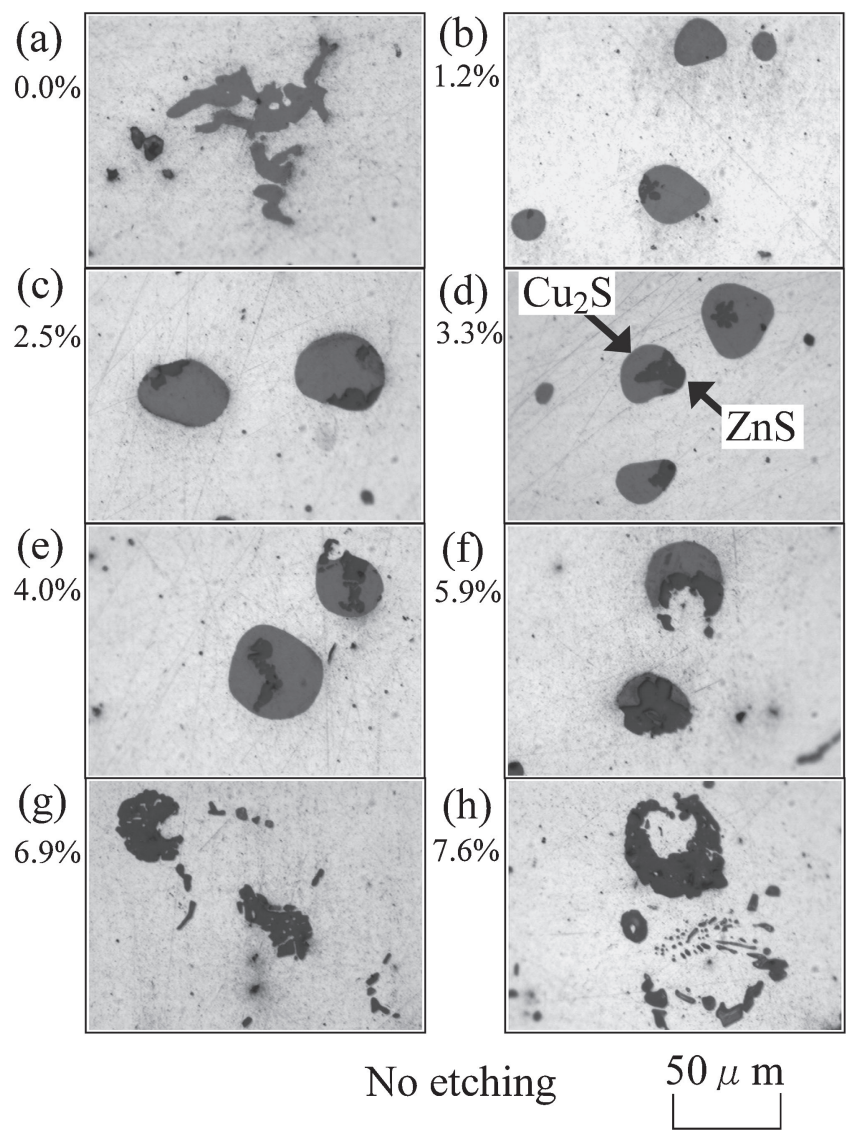

Fig. 2 Change in microstructure of sulfide with zinc content. Percentages in figures correspond to mass \% of zinc in alloys.

solid copper and the solid sulfide stably occurs following the $\mathrm{Cu}-\mathrm{Cu}_{2} \mathrm{~S}$ phase diagram. Also, the monotectic reaction with the solid copper and the liquid sulfide occurs metastably because the difference in the free energy between the eutectic reaction and the monotectic reaction is very small. ${ }^{11)}$ The ratio of the zinc sulfide increased with increasing zinc content, as shown in Figs. 2(b) to 2(e). The shape of sulfides including $\mathrm{Cu}_{2} \mathrm{~S}$ and $\mathrm{ZnS}$ changed from spherical into irregular at the zinc content more than 4.0 mass $\%$. The spherical sulfide is formed by the monotectic reaction, and the irregular shape sulfide is formed by the eutectic reaction. ${ }^{2)}$ In addition, the irregular shape sulfide mainly consists of the zinc sulfide. The zinc sulfide is formed as the solid phase, although the copper sulfide is formed as the liquid phase. The eutectic zinc sulfide was appeared when the zinc content was larger than 4.0 mass $\%$ [Fig. 2(e)]. Figure 3 shows a relationship between the zinc content and the ratio of the zinc sulfide in the sulfide particle in the sulfide dispersed alloy. The zinc sulfide ratio increased with increasing zinc content, especially more than 4.0 mass $\%$ of zinc. The increment of the zinc sulfide ratio was saturated at about 7 mass $\%$ or more.

\subsection{Effect of zinc sulfide ratio on machinability}

Figure 4 shows a relationship between the zinc content and the cutting index. ${ }^{1)}$ The larger number of the cutting index means the better machinability. The cutting index decreases with increasing zinc content. Figure 5 shows a relationship between the Rockwell hardness and the cutting index. The

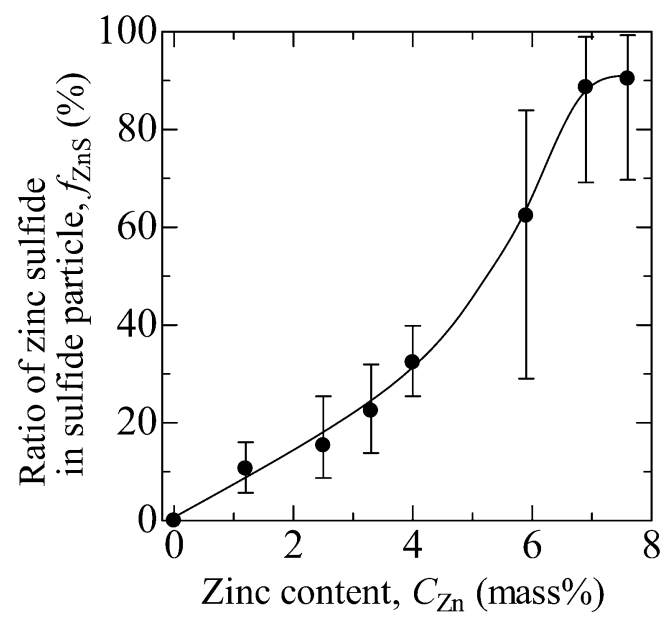

Fig. 3 Relationship between zinc content and ratio of zinc sulfide in sulfide particle.

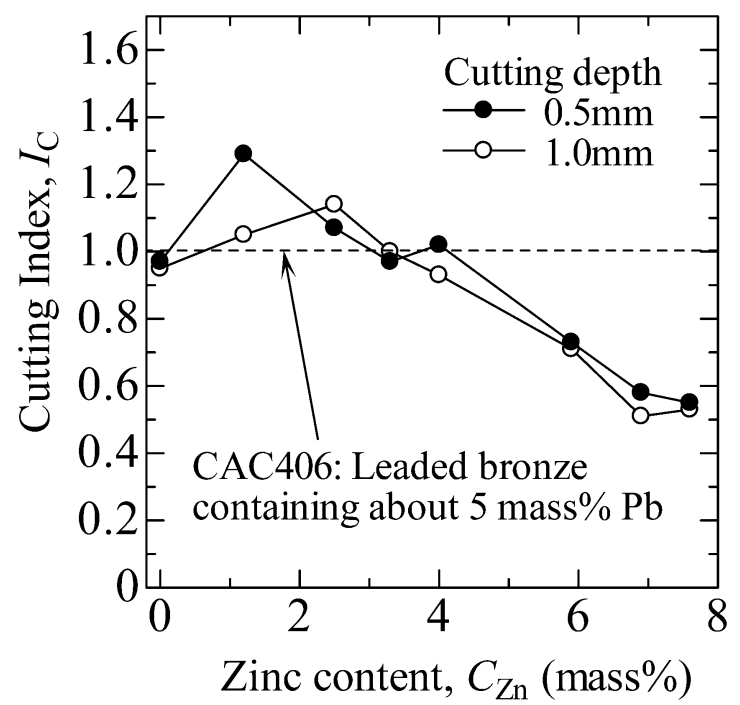

Fig. 4 Relationship between zinc content in sulfide dispersed lead free copper alloy and cutting index.

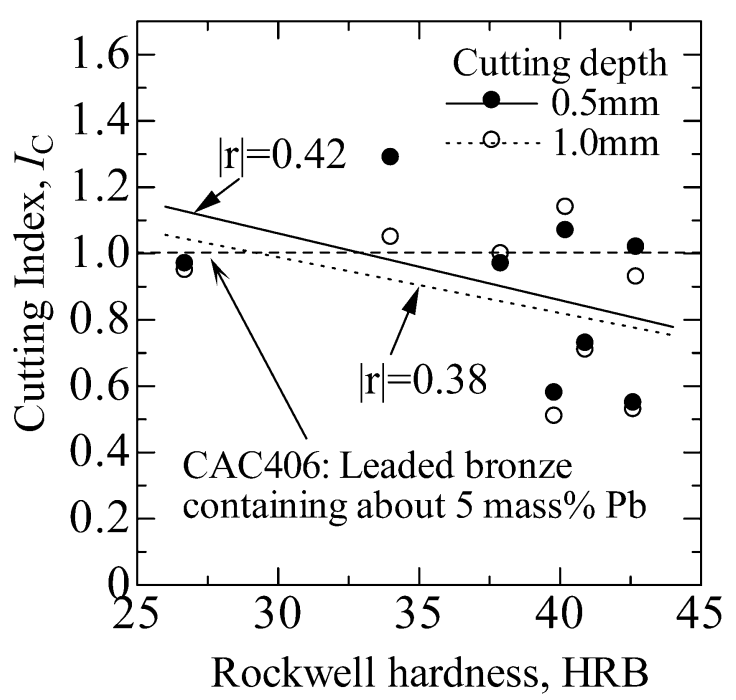

Fig. 5 Relationship between Rockwell hardness and cutting index. 


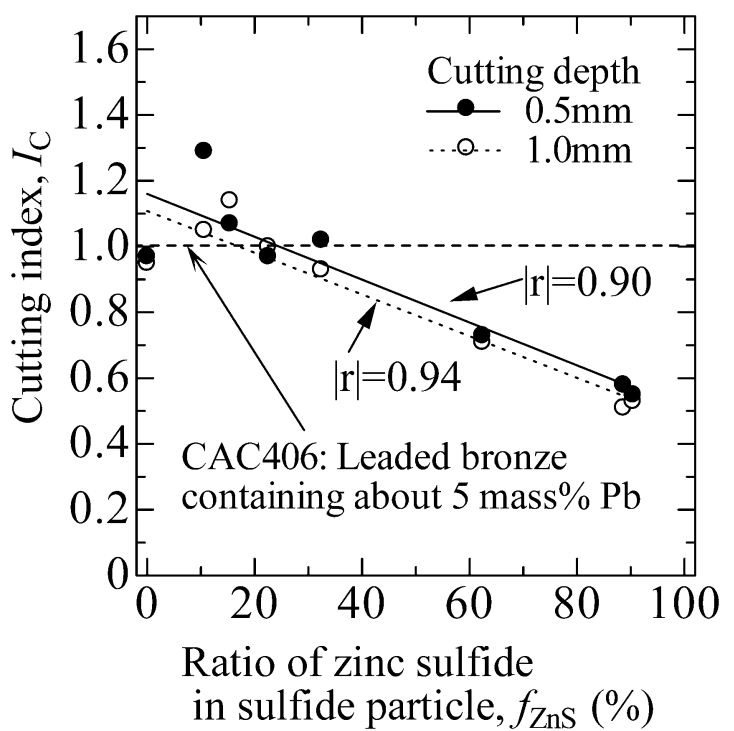

Fig. 6 Relationship between ratio of zinc sulfide in sulfide particle and cutting index.

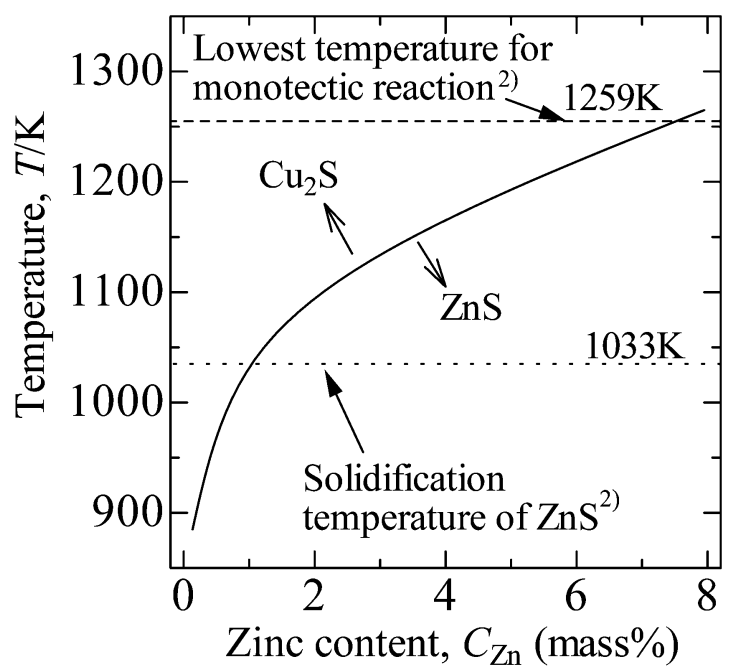

Fig. 7 Effect of zinc content on stable temperature of zinc sulfide by thermodynamic calculation. Zinc sulfide is stable in region below solid line.

correlation coefficients of the linear regression analysis are unexpectedly small, although the hardness might considerably affect the machinability. Figure 6 shows a relationship between the ratio of the zinc sulfide in the sulfide particle and the cutting index. The cutting index decreases with increasing zinc sulfide ratio. The correlation coefficients of the liner regression analysis are close to 1.0 , and the relationship is highly correlated. It is obvious that the major factor to decrease the machinability is the ratio of the zinc sulfide in sulfide particle.

\subsection{Formation of zinc sulfide}

Figure 7 shows the effect of the zinc content on the stable temperature range of the zinc sulfide by the thermodynamic calculation. Below the solid line, the zinc sulfide exists stably. The dotted line shows the solidification temperature of the zinc sulfide.2) The dashed line shows the lowest

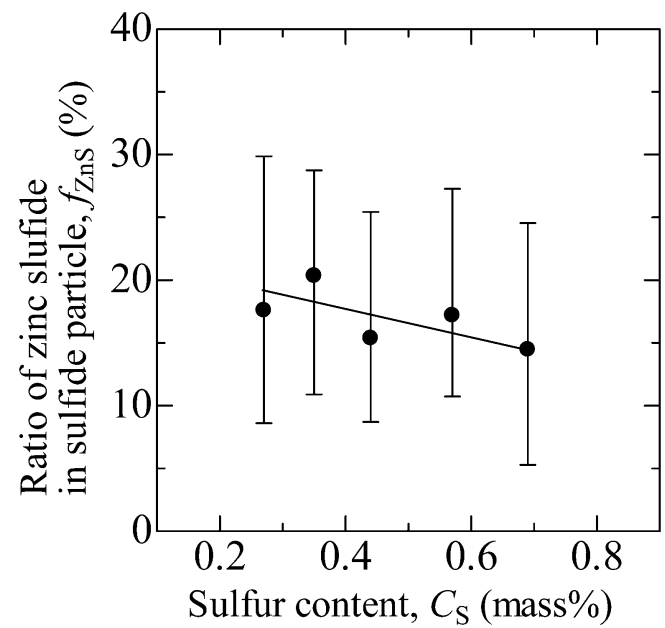

Fig. 8 Relationship between sulfur content and ratio of zinc sulfide in sulfide particle.

temperature for the monotectic reaction. ${ }^{2)}$ The stable temperature of the zinc sulfide increases with increasing zinc content. The zinc content in which the zinc sulfide exists stably is over 7.8 mass \% at the lowest temperature of the monotectic transformation. According to the figure, the zinc sulfide in the castings prepared in the present study should not be formed at the lowest temperature of the monotectic transformation because 7.6 mass\% of zinc is the maximum content in the present study. However, the zinc sulfide was formed as shown in Fig. 2. Two reasons why the zinc sulfide was formed are considered. First is the intermediate formation of the zinc sulfide in the copper sulfide. During solidification, the copper sulfide was formed according to the $\mathrm{Cu}_{2} \mathrm{~S}-\mathrm{ZnS}$ phase diagram. ${ }^{12)}$ In the copper sulfide, the zinc sulfide was dissolved, and precipitated in the copper sulfide during cooling due to poor solubility of zinc in the copper sulfide. The spherical sulfide, as shown in Fig. 2, is formed as the liquid phase by the monotectic reaction, and the zinc sulfide forms in the liquid after cooling, as was observed in the previous work. ${ }^{2)}$ The second reason is underestimation of the zinc activity. The zinc activity might be larger than the calculated value because of the increment of the zinc content in the melt due to segregation during solidification. The interaction between tin, nickel and sulfur might increase the zinc activity.

Figure 8 shows a relationship between the sulfur content and the ratio of the zinc sulfide in the sulfide particle in the sulfide dispersed alloy of S-1, S-2, S-3, S-4, and ZN-4. In the alloy, the zinc content was between 2.2 and 3.3 mass\%. The zinc sulfide ratio has a tendency to decrease with increasing sulfur content with large scatter. This tendency can be explained as follows. The ratio of the liquid at the eutectic/ monotectic temperature increases with increasing sulfur content because the alloy composition approaches the eutectic/monotectic composition. Because of the low liquid ratio, the zinc content in the liquid at the eutectic/monotectic temperature is smaller than that in the alloy of lower sulfur content. The decrease in the zinc content in the liquid leads to the decrease in the zinc content in the sulfide. The decrement of the zinc content in the sulfide may provide excellent cutting property because of the decrement of the zinc sulfide 


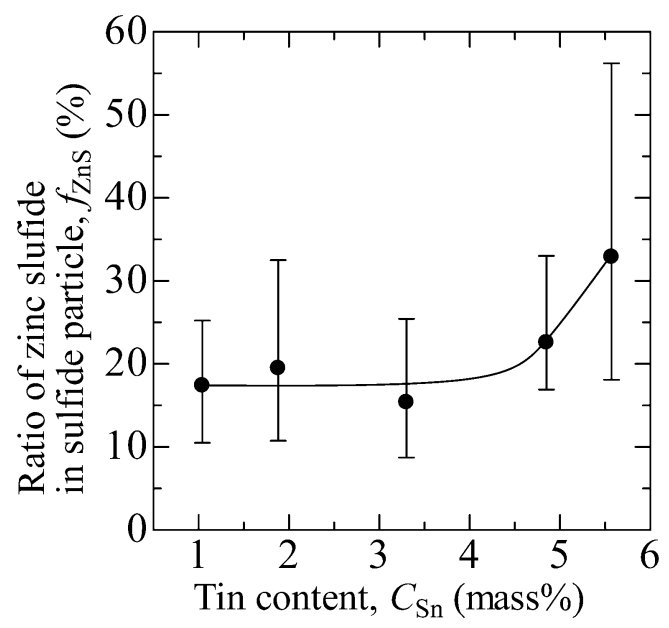

Fig. 9 Relationship between tin content and ratio of zinc sulfide in sulfide particle.

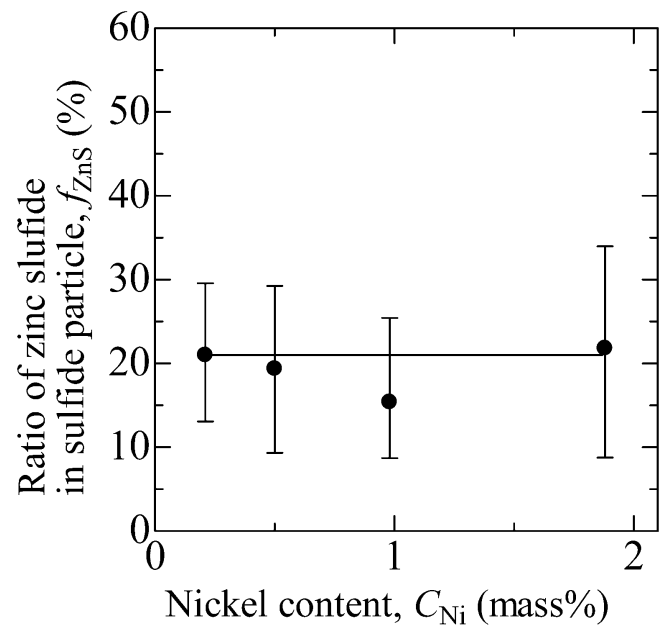

Fig. 10 Relationship between nickel content and ratio of zinc sulfide in sulfide particle.

in the dispersed sulfide. Figure 9 shows a relationship between the tin content and the ratio of the zinc sulfide in the sulfide particle in the sulfide dispersed alloy of $\mathrm{SN}-1$, $\mathrm{SN}-2, \mathrm{SN}-3$, and $\mathrm{ZN}-4$. In the alloy, the zinc content was between 2.4 and 3.3 mass $\%$. The zinc sulfide ratio was almost constant when the tin content was less than about 4 mass\%, and increased with the tin content when the tin content was larger than about 4 mass $\%$. It was thought that at larger tin content, the tin oxide was formed and acted as the nucleation site of the zinc sulfide due to the solubility limit of the tin oxide. Figure 10 shows a relationship between the nickel content and the ratio of the zinc sulfide in the sulfide particle in the sulfide dispersed alloy of NI-1, NI-2, NI-3, and ZN-4. In the alloy, the zinc content was between 1.9 and 3.3 mass $\%$. The zinc sulfide ratio was almost constant when the nickel content was less than about 2 mass $\%$. It is considered that the effect of nickel on the zinc activity is negligible in the alloy.

\section{Conclusions}

The effect of the zinc sulfide ratio on the machinability and the effect of alloying elements on the zinc sulfide ratio in the lead free bronze castings with the dispersed sulfide particles were studied by the microstructural analysis of the zinc sulfide and the thermodynamic calculation of the sulfide formation.

(1) The machinability is improved by reducing in the ratio of the zinc sulfide in the sulfide particle.

(2) The zinc sulfide ratio increases with increasing zinc content, especially above 4 mass $\%$ of the zinc.

(3) There is no effect of the tin content on the zinc sulfide ratio when the tin content is less than 4 mass $\%$, although the zinc sulfide ratio increases with increasing tin content more than 4 mass $\%$.

(4) There is no effect of nickel on the zinc sulfide ratio.

\section{Acknowledgement}

This research was supported by Kansai University's Overseas Research Program for the year of 2008.

\section{REFERENCES}

1) T. Maruyama, H. Abe, M. Matsubayashi, N. Maru, T. Akashi, T. Tachibana and T. Kobayashi: J. JFS 81 (2009) 667-673.

2) T. Kobayashi, I. Akashi, T. Maruyama, H. Abe, T. Sugitani and H. Wakai: J. JFS 81 (2009) 650-660.

3) H. Abe, T. Maruyama, T. Yasu, R. Matsubayashi and T. Kobayashi: J. JFS 81 (2009) 661-666.

4) T. Maruyama, H. Wakai, T. Kobayashi and H. Abe: Trans. Am. Foundry Soc. 116 (2008) 299-307.

5) M. Stucky, T. Monat and B. Luciani: Fonderie Fondeur Aujour'hui 261 (2007) 20-34.

6) B. Korojy, L. Ekbom and H. Fredriksson: Int. J. Cast Met. Res. 22 (2009) 179-182.

7) A. R. Singer and S. A. Cottrell: J. Inst. Met. 73 (1947) 33.

8) J. C. Borland: British Weld. J. 7 (1960) 580.

9) A. Roine: Outokumpu HSC Chemistry 5.1, (Outokumpu Research, 2002).

10) T. Azakami and A. Yazawa: J. Min. Metall. Inst. Japan 84 (1968) 16631668.

11) K. Oikawa, Y. Kawashita, H. Ohtani, K. Ishida and T. Nishizawa: J. Japan Inst. Metals 59 (1995) 1207-1214.

12) I. D. Olekseyuk, I. V. Dudchak and L. V. Piskach: J. Alloy. Compd. 368 (2004) 135-143. 